\title{
An alternate approach to valve replacement in patients with mitral stenosis and severely calcified annulus
}

\author{
Sameh M. Said, MD, and Hartzell V. Schaff, MD, Rochester, Minn
}

A severely calcified mitral annulus represents a unique challenge during mitral valve replacement. To ensure proper healing of the sewing ring of the prosthesis and to avoid periprosthetic regurgitation, the mitral annulus often must be debrided for secure attachment. However, the extensive debridement that can be required in some cases could increase the risk of atrioventricular groove disruption, with a subsequent increase in morbidity and mortality. Bypass of the mitral valve with a left atrial to left ventricular-valved conduit has been described for difficult cases with congenital mitral valve stenosis. In our report, we describe its use as a safe alternative to standard mitral valve replacement in a patient with a densely calcified annulus and severe mitral stenosis. (J Thorac Cardiovasc Surg 2014;147:e76-8)

Several techniques have been described to treat a heavily calcified mitral valve (MV) annulus during MV replacement. Extensive debridement can be necessary to secure the prosthesis. Some surgeons have used patch reinforcement of the annulus after debridement and before suture placement. Another technique is to place the sutures from the atrial side under the annular calcifications through the free edge of the leaflet and then, finally, through the sewing ring of the prosthesis; however, this technique increases the risk of circumflex coronary artery injury.

Extensive debridement of the MV annulus can increase the risk of atrioventricular groove disruption. However, this risk can be avoided with the use of a valved conduit from the left atrium (LA) to the left ventricle (LV). This technique has been described in the management of complex congenital mitral stenosis and in a single report as an alternative to MV replacement with heavily calcified annulus. We describe a patient who underwent LA-to-LV bypass for severe mitral stenosis with a severely calcified annulus.

\section{CASE REPORT}

A 44-year-old woman with end-stage renal disease was referred to our institution because of shortness of breath and heart failure that had required frequent hospitalizations. Other significant medical history included diabetes mellitus and significant peripheral arterial disease.

The preoperative chest radiograph revealed an enlarged cardiac silhouette, straightening of the left heart border,

From the Division of Cardiovascular Surgery, Mayo Clinic, Rochester, Minn. Disclosures: Authors have nothing to disclose with regard to commercial support. Received for publication Feb 10, 2014; accepted for publication Feb 14, 2014; available ahead of print March 20, 2014

Address for reprints: Hartzell V. Schaff, MD, Division of Cardiovascular Surgery, Mayo Clinic, 200 First St SW, Rochester, MN 55905 (E-mail: schaff@mayo.edu). $0022-5223 / \$ 36.00$

Copyright $($ c 2014 by The American Association for Thoracic Surgery http://dx.doi.org/10.1016/j.jtcvs.2014.02.039 and Kerley's B lines. On the transthoracic echocardiogram, severe stenosis was found of the MV and aortic valve (mean MV gradient, $16 \mathrm{~mm} \mathrm{Hg}$; mean aortic valve gradient, $64 \mathrm{~mm} \mathrm{Hg}$ ), with prominent calcification of the MV annulus and intervalvular fibrosa (Figure 1). The ejection fraction was $73 \%$.

Because of her New York Heart Association class IV symptoms, surgery was undertaken with plans for aortic valve and MV replacement. Through a median sternotomy, cardiopulmonary bypass was initiated using aortic and right atrial cannulas. After aortic crossclamping and cardioplegic arrest, the MV was evaluated through a left atriotomy. In addition to extreme annular calcification, the anterior and

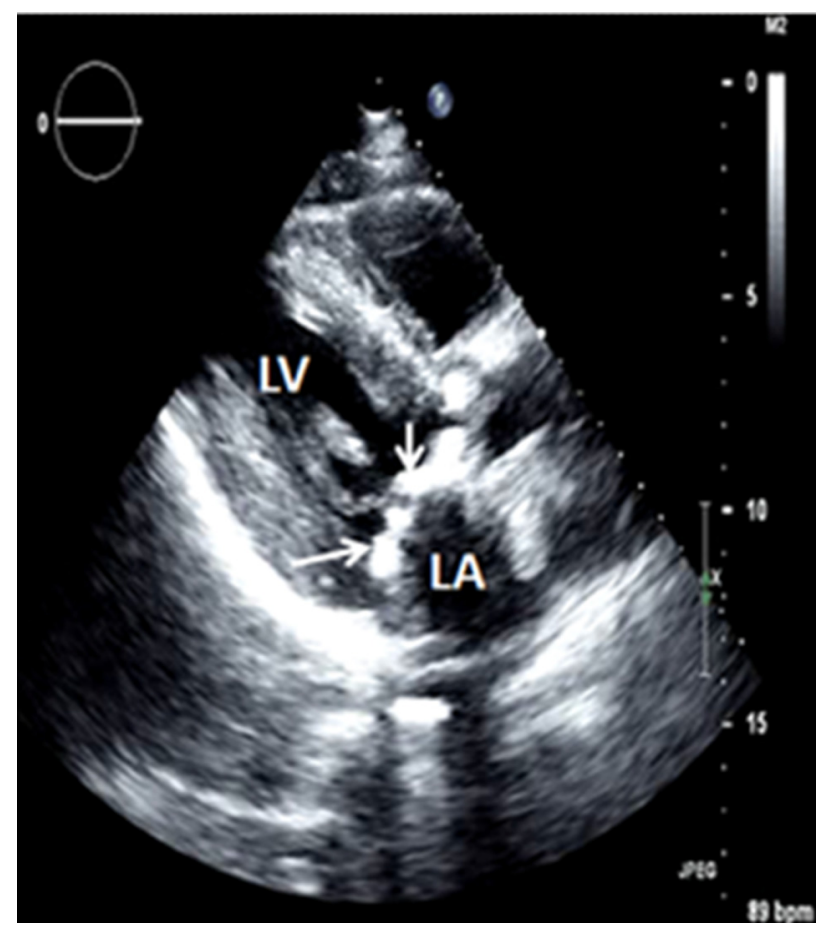

FIGURE 1. A, Preoperative transthoracic echocardiogram showing prominent calcification of the mitral annulus and intervalvular fibrosa (white arrows). $L V$, Left ventricle; $L A$, left atrium. 


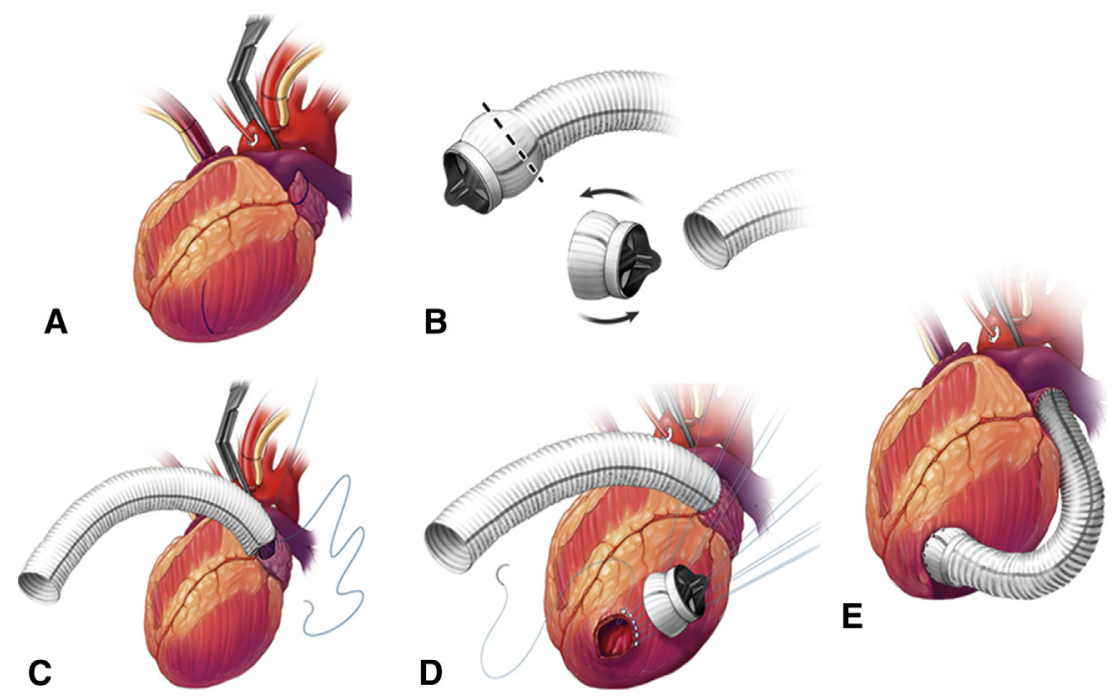

FIGURE 2. A, The conduit was placed between the left atrial appendage and left ventricular apex. B, The long limb of the valved conduit was excised, and the graft was excised down to approximately $2 \mathrm{~cm}$ above the valve. Next, the valve was turned upside down before it was sewn to the ventricle. C, The long limb of the graft was sewn to the amputated left atrial appendage. D, An apical left ventriculotomy was made, and the remaining portion of the conduit was beveled and sewn to the left ventricular apex using multiple interrupted 3-0 Prolene sutures. E, The 2 portions of the valved conduit were then sewn together to complete the left atrial-to-left ventricular bypass.

posterior leaflets were both heavily calcified. Standard aortic valve replacement was performed using a $21-\mathrm{mm}$ bileaflet mechanical valve.

Excision of the MV and surrounding calcium was considered risky, and, because the mitral regurgitation was minimal, we proceeded with MV bypass using a LA-to-LV conduit. A 23-mm mechanical aortic-valved conduit was used. We excised the long limb of the valved conduit and excised the graft down to approximately $2 \mathrm{~cm}$ above the valve (Figure 2, B). The LA appendage was
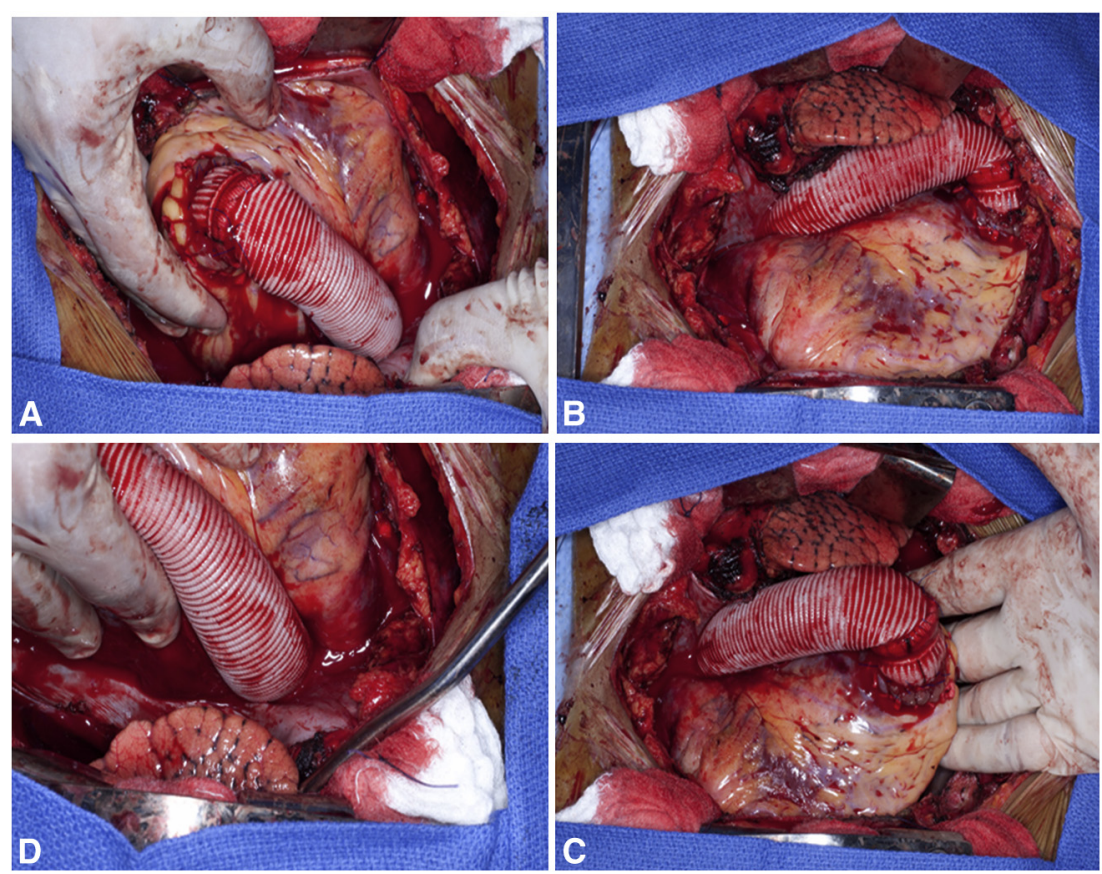

FIGURE 3. Intraoperative photographs showing the completed left atrial appendage to left ventricular bypass. A, The left ventricular apex has been lifted to show the location of the distal anastomosis. Note that the conduit valve has been positioned as close to the apex as possible. B and C, The conduit was located along the left side of the heart, representing the shortest possible distance from the left atrium to the left ventricle. D, The proximal anastomosis where the long graft of the conduit was connected to the left atrial appendage. 
amputated (Figure 2, $A$ ), and the long limb of the graft was sewn to the LA appendage (Figure 2,C) using continuous 4-0 Prolene suture. An apical left ventriculotomy was made (Figure 2,D), and the remaining portion of the conduit was beveled and sewn to the LV apex using multiple interrupted 3-0 Prolene suture (Figure 2,D). The 2 portions of the valved conduit were then sewn together using continuous 4-0 Prolene suture (Figure 2, E). We de-aired the graft and LA before closure. Cardiopulmonary bypass was discontinued without difficulty, and sinus rhythm returned spontaneously. The cardiopulmonary bypass and aortic crossclamp time was 86 and 79 minutes, respectively. The gradient from the LA to the LV was minimal. Her postoperative course was uneventful, anticoagulation was initiated, and she was dismissed in satisfactory condition on the eighth postoperative day.

\section{DISCUSSION}

Mitral annular calcification has been a major challenge during MV replacement, and it can increase the perioperative risk considerably. Debridement of the calcified annulus will be required to seat the prosthesis properly and avoid periprosthetic regurgitation. However, aggressive decalcification can result in fatal complications such as atrioventricular groove disruption. Other investigators have described placement of the valve sutures around the calcifications; however, this technique can increase the risk of circumflex coronary artery injury and will not be applicable to patients with very extensive calcifications.

Adjunctive techniques have been described to treat a heavy calcified annulus, such as patch reinforcement of the decalcified annulus and using the anterior leaflet to support the posterior annulus after debridement. ${ }^{1}$ Intra-atrial placement of the prosthesis was described; however, this will leave a portion of the atrium under LV pressure and can lead to dissection or tearing of the atrial wall. ${ }^{2}$

Extracardiac conduits have been used extensively on the right side of the heart in complex congenital heart defects. ${ }^{3}$ The use of extracardiac conduits on the left side has usually been limited to an LV apical-to-aortic conduit for complex
LV outflow tract obstruction. ${ }^{4}$ LA-to-LV bypass using a valved conduit has been previously described to correct congenital mitral stenosis ${ }^{5}$ and as an alternative to MV replacement in the presence of a severely calcified annulus in adults.

Our technique differs slightly from that described by Wright et al. ${ }^{6}$ In their description, the proximal anastomosis was made to the standard left atriotomy; the graft then had a c-shaped configuration along the right atrial free wall. In their illustration, the prosthetic valve was located in the middle of the conduit, leaving a long segment between the valve and the LV apex. This long conduit would create a noncontractile volume to the LV and could theoretically increase the risk of valve thrombosis. In our technique, we minimized the conduit length by making the proximal anastomosis to the amputated left atrial appendage, and we positioned the valve prosthesis just at the left ventriculotomy. We believe it is important to place the conduit valve as close to the LV apex as possible to eliminate any dead space, which could can increase the risk of thrombus formation (Figure 3).

The technique of MV bypass with a valved conduit was relatively easy to perform and should be reproducible. It could represent a safe alternative to MV replacement in the presence of a heavily calcified annulus; however, it requires the presence of minimal or no leakage in the native $\mathrm{MV}$ to ensure proper function of the conduit valve.

\section{References}

1. Casselman FP, Gillinov AM, McDonald ML, Cosgrove DM III. Use of the anterior mitral leaflet to reinforce the posterior mitral annulus after debridement of calcium. Ann Thorac Surg. 1999;68:261-2.

2. Nataf P, Pavie A, Jault F, Bors V, Cabrol C, Gandjbakhch I. Intraatrial insertion of a mitral prosthesis in a destroyed or calcified mitral annulus. Ann Thorac Surg. $1994 ; 58: 163-7$

3. McGoon DC, Danielson GK, Puga FJ, Ritter DG, Mair DD, Ilstrup DM Late results after extracardiac conduit repair for congenital cardiac defects. Am J Cardiol. 1982;49:1741-9.

4. Crestanello JA, Zehr KJ, Daly RC, Orszulak TA, Schaff HV. Is there a role for the left ventricle apical-aortic conduit for acquired aortic stenosis? J Heart Valve Dis. 2004; $13: 57-62$

5. Lansing AM, Elbl F, Solinger RE, Rees AH. Left atrial-left ventricular bypass for congenital mitral stenosis. Ann Thorac Surg. 1983;35:667-9.

6. Wright JS, Thomson DS, Warner G. Mitral valve bypass by valved conduit. Ann Thorac Surg. 1981;32:294-6. 